\title{
Psychometric Validation of the Bahasa Malaysia Version of the EORTC QLQ-CR29
}

\author{
Bello Arkilla Magaji ${ }^{1,2,3 *}$, Foong Ming Moy ${ }^{1}$, April Camilla Roslani ${ }^{2,3}$, Chee Wei \\ Law $^{2}$, Farhana Raduan ${ }^{5}$, Ismail Sagap ${ }^{5}$
}

\begin{abstract}
Background: This study examined the psychometric properties of the Bahasa Malaysia (BM) version of the European Organization for Research and Treatment of Cancer (EORTC) Colorectal Cancer-specific Quality Of Life Questionnaire (QLQ-CR29). Materials and Methods: We studied 93 patients recruited from University Malaya and Universiti Kebangsaan Medical Centers, Kuala Lumpur, Malaysia using a self-administered method. Tools included QLQ-C30, QLQ-CR29 and Karnofsky Performance Scales (KPS). Statistical analyses included Cronbach's alpha, test-retest correlations, multi-traits scaling and known-groups comparisons. A p value $\leq \mathbf{0 . 0 5}$ was considered significant. Results: The internal consistency coefficients for body image, urinary frequency, blood and mucus and stool frequency scales were acceptable (Cronbach's alpha $\alpha \geq 0.65)$. However, the coefficients were low for the blood and mucus and stool frequency scales in patients with a stoma bag ( $\alpha=$ 0.46). Test-retest correlation coefficients were moderate to high (range: $r=0.51$ to 1.00 ) for most of the scales except anxiety, urinary frequency, buttock pain, hair loss, stoma care related problems, and dyspareunia $(r \leq 0.49)$. Convergent and discriminant validities were achieved in all scales. Patients with a stoma reported significantly higher symptoms of blood and mucus in the stool, flatulence, faecal incontinence, sore skin, and embarrassment due to the frequent need to change the stoma bag $(p<0.05)$ compared to patients without stoma. None of the scales distinguished between patients based on the KPS scores. There were no overlaps between scales in the QLQ-C30 and QLQ-CR29 ( $<$ 0.40). Conclusions: the BM version of the QLQ-CR29 indicated acceptable psychometric properties in most of the scales similar to original validation study. This questionnaire could be used to complement the QLQ-C30 in assessing HRQOL among BM speaking population with colorectal cancer.
\end{abstract}

Keywords: Colorectal carcinoma - EORTC QLQ-CR29 - validity - reliability - Bahasa Malaysia

Asian Pac J Cancer Prev, 16 (18), 8101-8105

\section{Introduction}

Assessment of Health-related quality of life (HRQOL) has now become an integral part of cancer researches including cancer of the colorectum. This is because of its importance is guiding the investigators, clinicians and policy makers in assessing the role of treatment or interventions in cancer care (Farkkila et al., 2013; Hung et al., 2013). There is rising incidence/prevalence of colorectal cancer in malaysia (Ulaganathan et al., 2012; Norwati et al., 2014) and the colon and rectal cancers combined ranked the second most frequent cancer among malaysians (Shah et al., 2014). In addition, there is an increasing interest in outcome resaerches related to colorectal cancer (Natrah et al., 2012; Puteh et al., 2013). This prompt the need for a valid measurement instrument for HRQOL. The existence of the European Organization for Research and Treatment of Cancer colorectal cancer specific questionnaire (EORTC QLQ-CR38 and QLQCR29) means we need not develop a new instrument (Sprangers et al., 1999; Whistance et al., 2009). The QLQCR29 module is an updated version of the QLQ-CR38. The later comprises of 29 items assessing symptoms, treatment side-effects, body image, sexual dysfunction and concern about the future. The first nineteen questions are to be completed by all patients, while the remaining 10 questions are to be completed by sub-samples of patients (that is patients with stoma or without a stoma, males or females) respectively (Whistance et al., 2009).

The earlier version (QLQ-CR38) first released over a decade ago (Sprangers et al., 1999), has been validated among patients with colorectal cancer in the Netherlands (Hasanah, 2003), Denmark (Thaysen et al., 2012), Japan (Tsunoda et al., 2008), France (Rotonda et

${ }^{1}$ Julius Centre University of Malaya, Department of Social \& Preventive Medicine, Faculty of Medicine, ${ }^{2}$ Department of Surgery, Faculty of Medicine, ${ }^{3}$ University of Malaya Cancer Research Institute (UMCRI), University of Malaya, ${ }^{5}$ Department of Surgery, Universiti Kebangsaan Malaysia Medical Centre, Kuala Lumpur, ${ }^{4}$ Department of Community Health, College of Health Sciences, Usmanu Danfodiyo University, PMB, Sokoto,Nigeria*For correspondence:drmagaji@siswa.um.edu.my, mbarkilla@gmail.com 
al., 2008) and Hong Kong Chinese (Law et al., 2008). The current version (QLQ-CR29) was first released in 2009 following an international validation study in seven European countries (Whistance et al., 2009). Was also subsequently validated separately in Spain (Arraras et al., 2011), Columbia (Calvo et al., 2010) Portugal(Silva; 2012), China (Peng et al., 2011), and Poland (Nowak et al., 2011). However, no such study has ever been conducted in Malaysia.

This study is part of a larger project on survival and quality of life outcomes of patients with colorectal cancer. Earlier report indicated that all Malaysians ethnic groups are affected by colorectal cancer though the incidence is higher in Chinese groups compared to other ethnic groups (Magaji et al., 2014). However, the Bahasa Malaysia is the national language of Malaysia. In this paper, we aimed to evaluate the psychometric properties of the Bahasa Malaysia version of the QLQ-CR29 questionnaire in Malaysian patients with colorectal cancer. This study is the first to report on the psychometric properties and clinical validity of the Bahasa Malaysia versions of the EORTC QLQ-CR 29. This questionnaire will complement the EORTC core questionnaire QLQ-CR 30 in assessing HRQOL among patients with colorectal cancer.

\section{Materials and Methods}

Participants for this study were recruited from the University Malaya Medical Centre (UMMC) and University Kebangsaan Malaysia medical centre (UKMMC). Baseline characteristics of the patients were obtained from medical records. The HRQOL data was obtained using the Bahasa Malaysia versions of the QLQ-C30 and QLQ-CR29. The translated version of the QLQ-C30 was obtained from the EORTC quality of life department. The QLQ-CR29 was obtained as an original English version and subsequently translated into Bahasa Malaysia by a team of experts translators. The two questionnaires were pilot tested prior to the field work. Written inform consent was obtained from all patients. Patients completed the questionnaires at the respective surgical clinic days in the two hospitals. In addition, attending surgeons completed the Karnofsky Performance Scale (KPS).

Descriptive analysis was performed; continuous data was summarized using mean and standard deviations while categorical data was summarized using proportions. The internal consistency of the multi-item scales was examined by the use of Cronbach's alpha coefficient. A coefficient of $\geq .70$ is considered acceptable. Test-retest correlation coefficient was used to examine test-retest reliability. Multi-trait scaling analyses were used to examine the scale structures (convergent and discriminant validity). A criterion considered is that each item own scale correlation should exceed 0.4 for convergent validity to be achieved. The discriminant validity measures item correlation with other scales. It is hypothesized that the item's own correlation should be higher than with the other scales. Clinically known groups differences were examined in patients with and without stoma, and based on the KPS score of $\leq 80 \%$, and $\geq 81 \%$ ). Wilcoxon rank sum test was used in this regard. All analyses were done via SPSS version 21.0 for Windows, (SPSS Inc., and Chicago, Illinois, USA). A two-tailed probability value of 0.05 was used to determine the level of significance. Further details can be obtained in the published protocol (Magaji et al., 2012).

This project was approved by the ethics committees of the University of Malaya Medical Centre (PPUM/ UPP/300/02/02, MEC 770.2) and Universiti Kebangsaan Malaysia Medical Centre (Project code: FF-274-2011).

\section{Results}

Demographic and clinical characteristics

A total of 93 patients with colorectal cancer (UMMC 47, UKMMC 46) were studied. The mean age and standard deviation (SD) was 57(SD 11) years (range 25-74). There were more males, Malays, active civil servants and about one quarter was not formally educated. Advanced stage (Dukes' C/D) cancers accounted for $61 \%$. The mean KPS was $80 \%$ (SD 10) and $32 \%$ of patients had a stoma (Table 1).

\section{Internal consistency and test-retest analyses}

The internal consistencies were computed for all the patients, and separately for patients with and without stoma. Overall, the internal consistency coefficients for body image, urinary frequency, blood and mucus and stool

Table 1. Demographic and Clinical Features of the Patients $(\mathbf{n = 9 3})$

\begin{tabular}{|c|c|c|}
\hline \multicolumn{2}{|l|}{ Characteristics } & Number $(\%)$ \\
\hline \multicolumn{3}{|l|}{ Age (years) } \\
\hline Mean (SD) & & $57(11)$ \\
\hline Range & & $25-74$ \\
\hline \multirow[t]{2}{*}{ Gender } & Male & $55(59)$ \\
\hline & Female & $38(41)$ \\
\hline \multirow[t]{3}{*}{ Ethnic groups } & Malays & $71(76)$ \\
\hline & Indians & $18(20)$ \\
\hline & Others & $4(4)$ \\
\hline \multirow[t]{5}{*}{ Educational status } & Primary & $17(18)$ \\
\hline & Secondary & $24(26)$ \\
\hline & Tertiary & $12(13)$ \\
\hline & Not formally educatec & d 26(28) \\
\hline & Unknown & $14(15)$ \\
\hline \multirow[t]{4}{*}{ Employment status } & Fulltime & $42(45)$ \\
\hline & Retired & $36(39)$ \\
\hline & Unemployed & $7(8)$ \\
\hline & Unknown & $8(9)$ \\
\hline \multirow[t]{3}{*}{ Site } & Colon & $48(52)$ \\
\hline & Rectal & $35(38)$ \\
\hline & Unknown & $10(10)$ \\
\hline \multirow[t]{5}{*}{ Dukes stage } & A & 4(4) \\
\hline & $\mathrm{B}$ & $26(28)$ \\
\hline & $\mathrm{C}$ & $17(18)$ \\
\hline & $\mathrm{D}$ & $40(43)$ \\
\hline & Unknown & $6(7)$ \\
\hline \multirow[t]{2}{*}{ Stoma } & Yes & $32(34)$ \\
\hline & No & $61(66)$ \\
\hline \multirow[t]{4}{*}{ Karnofsky performance status } & Mean (SD) & $80(10)$ \\
\hline & Range & $50-90$ \\
\hline & $\leq 80$ & $50(54)$ \\
\hline & $\geq 81$ & $43(46)$ \\
\hline
\end{tabular}


Table 2. Internal Consistency Coefficients (Cronbach's alpha) for the Bahasa-Malaysian and Original Validation Study

\begin{tabular}{lccccc}
\hline Scale & \multicolumn{2}{c}{ All patients } & \multicolumn{2}{c}{ With Stoma } & \multicolumn{2}{c}{ Without Stoma } \\
& $\begin{array}{c}\text { Bahasa } \\
\text { Malaysia }\end{array}$ & $\begin{array}{c}\text { Original } \\
\text { validation }\end{array}$ & $\begin{array}{c}\text { Bahasa } \\
\text { Malaysia }\end{array}$ & $\begin{array}{c}\text { Original } \\
\text { validation }\end{array}$ & $\begin{array}{c}\text { Bahasa } \\
\text { Malaysia }\end{array}$ \\
\hline Body image & 0.78 & 0.84 & 0.81 & 0.82 & 0.77 \\
Urinary frequency & 0.74 & 0.75 & 0.74 & 0.8 & 0.74 \\
Blood and mucus & $0.66^{*}$ & 0.69 & $0.49 *$ & 0.54 & 0.76 \\
Stool frequency & 0.75 & 0.7 & $0.46^{*}$ & 0.78 & 0.72 \\
\hline
\end{tabular}

Original validation study by Whistance, R. N., et al. (2009)

Table 3. Convergent Validity in the Bahasa Malaysia Version and Original Validation Study EORTC QLQ-CR29

\begin{tabular}{|c|c|c|c|c|c|c|}
\hline \multirow[b]{2}{*}{ Scales } & \multicolumn{2}{|c|}{ All patients } & \multicolumn{2}{|c|}{ With Stoma } & \multicolumn{2}{|c|}{ Without Stoma } \\
\hline & $\begin{array}{c}\text { Bahasa } \\
\text { Malaysia }\end{array}$ & $\begin{array}{c}\text { Original } \\
\text { validation }\end{array}$ & $\begin{array}{c}\text { Bahasa } \\
\text { Malaysia }\end{array}$ & $\begin{array}{c}\text { Original } \\
\text { validation }\end{array}$ & $\begin{array}{c}\text { Bahasa } \\
\text { Malaysia }\end{array}$ & $\begin{array}{c}\text { Original } \\
\text { validation }\end{array}$ \\
\hline Body image & $0.79-0.86$ & $0.65-0.77$ & $0.84-0.88$ & $0.61-0.79$ & $0.78-0.85$ & $0.64-0.73$ \\
\hline Urinary frequency & $0.88-0.90$ & $0.60-0.60$ & $0.88-0.91$ & $0.56-0.56$ & $0.89-0.89$ & $0.67-0.67$ \\
\hline Blood and mucus & $0.83-0.90$ & $0.53-0.53$ & $0.75-0.87$ & $0.57-0.57$ & $0.88-0.92$ & $0.37-0.37$ \\
\hline Stool frequency & $0.87-0.93$ & $0.57-0.57$ & $0.72-0.89$ & $0.54-0.54$ & $0.93-0.95$ & $0.65-0.65$ \\
\hline
\end{tabular}

Original validation study by Whistance, R. N., et al. (2009)

Table 4. Discriminant Validity in the Bahasa Malaysia Version and Original Validation Study EORTC QLQ-CR29

\begin{tabular}{|c|c|c|c|c|c|c|}
\hline \multirow[b]{2}{*}{ Scale } & \multicolumn{2}{|c|}{ All patients } & \multicolumn{2}{|c|}{ With Stoma } & \multicolumn{2}{|c|}{ Without Stoma } \\
\hline & $\begin{array}{c}\text { Bahasa } \\
\text { Malaysia }\end{array}$ & $\begin{array}{c}\text { Original } \\
\text { validation }\end{array}$ & $\begin{array}{c}\text { Bahasa } \\
\text { Malaysia }\end{array}$ & $\begin{array}{c}\text { Original } \\
\text { validation }\end{array}$ & $\begin{array}{l}\text { Bahasa } \\
\text { Malaysia }\end{array}$ & $\begin{array}{c}\text { Original } \\
\text { validation }\end{array}$ \\
\hline Body image & $0.06-0.34$ & $0.00-0.43$ & $0.04-0.29$ & $0.01-0.39$ & $0.07-0.41$ & $0.00-0.48$ \\
\hline Urinary frequency & $0.08-0.24$ & $0.00-0.21$ & $0.05-0.73$ & $0.01-0.25$ & $0.07-0.28$ & $0.00-0.22$ \\
\hline Blood and mucus & $0.09-0.39$ & $0.00-0.25$ & $0.01-0.61$ & $0.01-0.38$ & $0.02-0.53$ & $0.00-0.34$ \\
\hline Stool frequency & $0.07-0.38$ & $0.03-0.46$ & $0.05-0.34$ & $0.00-0.49$ & $0.01-0.48$ & $0.02-0.41$ \\
\hline
\end{tabular}

Original validation study by Whistance, R. N., et al. (2009)

Table 5. Known Group Comparison for Patients with and without Stoma

\begin{tabular}{lccc}
\hline \multicolumn{4}{c}{ Presence of stoma } \\
Scales & Mes (n=32) & No (n=61) & \\
\hline Blood and mucus & $13.54(19.14)$ & $5.19(15.38)$ & $0.010 *$ \\
Flatulence & $36.45(30.95)$ & $19.13(27.53)$ & $0.001 *$ \\
Faecal incontince & $19.79(22.17)$ & $4.37(1287)$ & $<0.001 *$ \\
Sore skin & $22.92(26.01)$ & $6.56(20.02)$ & $<0.001 *$ \\
Embarrassed due to frequent bowel movement or need to change \\
stoma bag & $26.04(30.21)$ & $4.598(14.57)$ & $<0.001 *$ \\
\hline *Significant difference $(\mathrm{p}<.05)$ by Wilcoxon rank sum test
\end{tabular}

*Significant difference $(\mathrm{p}<.05)$ by Wilcoxon rank sum test

frequency scales were acceptable (Cronbach's alpha $\geq$ 0.65). However, the Cronbach's alpha coefficients were low for the blood and mucus as well as stool frequency scales in the subgroup of patients with a stoma bag $(\alpha=$ 0.46 ). Table 2 shows the Cronbach's alpha coefficient in our study and the original validation study.

The test-retest correlation coefficients were moderate to high (range: $r=0.51$ to 1.00 ) for most of the scales except anxiety $(r=0.30)$, urinary frequency $(r=0.45)$, buttock pain $(r=0.49)$, hair loss $(r=0.14)$, stoma care related problems $(r=0.41)$ and dyspareunia $(r=0.33)$.

\section{Multi-trait scaling}

The scale structure of the functioning scale (body image) and three multi-item symptoms scales (urinary frequency, blood and mucus and stool frequency) was confirmed.Analysis was performed in all patients, patients with and without stoma. The results indicated that both the convergent validity (correlation between items and its own scale $(r) \geq 0.40)$ and discriminant validities (item's own scale correlation higher than items correlation with other scales) were achieved in all level of analysis and for both patients with and without stoma (Table 3-4).

\section{Known group comparison}

Generally, patients with a stoma reported more gastrointestinal symptoms, sore skin around the stoma bag, and psychosocial disturbance due to the frequent need to change the stoma. For example, patients with a stoma reported significantly higher symptoms of presence of blood and mucus in the stool $(\mathrm{p}=0.010)$, flatulence $(\mathrm{p}=$ $0.004)$, faecal incontinence $(\mathrm{p}<0.001)$, sore skin around the stoma bag $(\mathrm{p}<0.001)$, and psychosocial disturbance in the form of embarrassment due to the frequent need to change the stoma bag $(\mathrm{p}<0.001)$ compared to patients without a stoma (Table 5).

None of the scales in the Bahasa Malaysia version showed a statistically significant difference in the comparison between patients with low and high KPS scores.

Interco relations between EORTC QLQ-C30 and QLQCR29

Numerous significant correlations were observed between domains in the EORTC QLQ-C30 and QLQCR29. These correlations were mostly weak correlations $(\mathrm{r} \leq 0.50)$. The strongest significant positive correlation 
was between financial difficulty and stoma care related problems $(r=0.71, p<0.001)$; this means, patients with stoma care related problems also suffered related financial difficulty. Similarly, the strongest significant negative correlation was between emotional functioning and stoma care related problems $(r=-0.71, p<0.001)$, this means patients with stoma care related problems reported poor emotional functioning.

\section{Discussion}

This study provides data on the psychometric properties of the Bahasa Malaysia version of the QLQCR29. The questionnaire was translated into the Bahasa Malaysia language, pilot tested and then examined for its psychometric properties in patients recruited from two referral center in Kuala Lumpur, Malaysia.

The internal consistency coefficients of the Bahasa Malaysia version were greater than the acceptable level of 0.70 in most of the scales examined. However, two multi-item symptom scales namely blood and mucus in stool and stool frequency scale failed to meet the minimum requirement for adequate internal consistency ( $\alpha \leq 0.70)$. The scales, however, indicated good internal consistency in non-stoma. Poor internal consistency for the stool frequency scale was observed in patients with a stoma bag. The poor internal consistency coefficient in the gastrointestinal symptom scales was consistent with several reports on both the earlier version (QLQ-CR38) and the current version (QLQ-CR29) (Law et al., 2008; Tsunoda et al., 2008; Whistance, et al., 2009; Arraras, et al., 2011; Nowak et al., 2011; Peng et al., 2011; Thaysen, et al.,2012). Our findings and those of the previous studies might be an indicator of the need to further refine the scale examining the presence of blood and mucus in the stool, and the utility of the stool frequency scale in patients with a stoma bag.

In this study, the test-retest correlation coefficients were high in most of the scales. The coefficients were high in all the scale (moderate to high agreement ICC $\geq$ 0.50 ) except for the urinary frequency, buttock pain, hair loss and dyspareunia. Thus, the Bahasa Malaysia version in this study indicated good reproducibility similar to the original international validation study Whistance, et al., 2009). Meanwhile, none of the later studies examined the test-retest reliability of the EORTC QLQ-CR29 to enable comparison.

The multi-trait scaling analyses confirm the proposed structure of the four multi-item scales. All items met the criteria for convergent and discriminant validity for all four multi-item scales. These findings are consistent with the original validation, and many other studies involving both the EORTC QLQ-CR38 and EORTC QLQ-CR29 (Arraras, et al., 2011; Whistance, et al., 2009; Thaysen, et al., 2012).

In our study, comparison between patients with and without a stoma bag revealed that in patients completing the Bahasa Malaysia version with a stoma were found to experience more leakage of blood and mucus in stool, flatulence, faecal incontinence, sore skin around the stoma bag, and embarrassment due to the frequent need to change the stoma bag/bowel movement. Our finding is consistent with previous studies indicating that creation of a stoma negatively affects specific aspects of colorectal cancer patients' health related quality of life (Sharpe 2011, Pachler 2012). Other reports regarding the QLQCR29 also suggest that that some but not all the scales/ items are useful in differentiating between clinically distinct patients groups (Thaysen, et al., 2012). Despite the fact that statistically significant difference was not observed in all the scales between groups based on KPS scores, patient with higher performance scores reports higher functioning and few symptoms. Previous studies indicate significant differences between patient with low performance and those in the high performance category (Whistance, et al., 2009, Arraras, et al., 2011). This is in contrast with previous studies where better performance of the questionnaires (EORTC QLQ-CR38 and/or EORTC QLQ-CR29) in differentiating between patients in the two spectrums of performance scales was found (Whistance, et al., 2009, Arraras, et al., 2011, Nowak, et al., 2011). Thus, the utility of the questionnaire items in differentiating between clinically distinct patient groups based on KPS needs further investigation in our setting.

There was no overlap between items in the QLQ-C30 and QLQ-CR29 except in few items examining closely related HRQOL issues. This indicates that the two questionnaires can be used together. This is evidenced by lack of significant correlations between items measuring unrelated concepts as well as significant correlations between scales measuring closely related concepts. The few instances where higher correlations were obtained were not unexpected. For example, the appetite loss and constipation items in the QLQ-C30 are closely related to the blood-mucus scale of the QLQ-CR29. Similarly, high correlation between emotional function and stoma care problem was not unusual. These findings are similar with the original validation and many other studies (Whistance, et al., 2009, Arraras, et al., 2011, Thaysen 2012). Our findings were in parallel with the original international validation study (Whistance, et al., 2009), and Spanish study (Arraras, et al., 2011). Other validations studies did not examine the correlations between QLQ-C30 and QLQ-CR29 scales to enable comparisons (Nowak et al., 2011; Thaysen, et al., 2012).

In conclusion, the Bahasa-Malaysia versions of the EORTC QLQ-CR29 show acceptable psychometric properties in most of the scales similar to original validation study conducted in seven European and many other studies. This study provides valid and reliable instruments that could be used to complement the EORTC QLQ-C30 in assessing HRQOL among Bahasa Malaysia speaking population with colorectal cancer. The BahasaMalaysia translated version of the EORTC QLQ-CR29 is readily available and can be obtained from the EORTC Quality of Life department for future research. Further studies involving large sample of patients with colorectal cancer at different spectrum of disease/treatment levels, as well as revision for the blood and mucus scale are recommended. 


\section{Acknowledgements}

This study was fully funded by the University of Malaya postgraduate fund with the following reference numbers (UM-IPPP PS212/2010A and PV015-2011B) and partially supported by the STeMM Programme, the University of Malaya/Ministry of Higher Education (UM/ MOHE) High Impact Research Grant (No: E00001020001).

\section{References}

Arraras JI, Suarez J, de la Vega FA, et al (2011). The EORTC quality of life questionnaire for patients with colorectal cancer: EORTC QLQ-CR29 validation study for Spanish patients. Clinical \& Translational Oncology, 13, 50-6.

Calvo Ó, Oliveros R, Sánchez R (2010). Adaptación cultural del formulario EORTC QLQ CR-29 para su aplicación en pacientes con cáncer de recto en el Instituto Nacional de Cancerología de Colombia. Revista Colombiana de Cancerología, 14, 189-98.

Farkkila N, Sintonen H, Saarto T, et al (2013). Health-related quality of life in colorectal cancer. Colorectal Dis, 15, 215-22.

Hasanah CI (2003). Approaches and methodological as well as interpretative issues in quality of life research in malaysia. Malays J Med Sci, 10, 60-5.

Hung HC, Chien TW, Tsay SL, et al (2013). Patient and clinical variables account for changes in health- related quality of life and symptom burden as treatment outcomes in colorectal cancer: a longitudinal study. Asian Pac J Cancer Prev, 14, 1905-9.

Law CC, Lam WWT, Fu YT, et al (2007). The Chinese version of the EORTC colorectal cancer-specific quality of life questionnaire module (QLQ-CR38): Validity and reliability. Psycho-Oncology, 16, 142.

Law CC, Lam WWT, Fu YT, et al (2008). Validation of the chinese version of the EORTC colorectal cancer-specific quality-of-life questionnaire module (QLQ-CR38). Journal of Pain and Symptom Management, 35, 203-13.

Magaji BA, Moy FM, Roslani AC, et al (2014). Descriptive epidemiology of colorectal cancer in University Malaya Medical Centre, 2001 to 2010. Asian Pac J Cancer Prev, 15, 6059-64.

Magaji BA, Moy FM, Roslani AC, et al (2012). Health-related quality of life among colorectal cancer patients in Malaysia: a study protocol. BMC Cancer, $\mathbf{1 2}, 384$.

Natrah MS, Ezat S, Syed MA, et al (2012). Quality of life in Malaysian colorectal cancer patients: a preliminary result. Asian Pac J Cancer Prev, 13, 957-62.

Norwati D, Harmy MY, Norhayati MN, et al (2014). Colorectal cancer screening practices of primary care providers: results of a national survey in Malaysia. Asian Pac J Cancer Prev, 15, 2901-4.

Nowak W, Tobiasz-Adamczyk B, Brzyski P, et al (2011). Adaptation of quality of life module EORTC QLQ-CR29 for Polish patients with rectal cancer: initial assessment of validity and reliability. Pol Przegl Chir, 83, 502-10.

Peng JJ, Shi DB, Goodman KA, et al (2011). Early results of quality of life for curatively treated rectal cancers in Chinese patients with EORTC QLQ-CR29. Radiation Oncology, 6.

Rotonda C, Conroy T, Mercier M, et al (2008). Validation of the French version of the colorectal-specific quality-of-life questionnaires EORTC QLQ-CR38 and FACT-C. Quality of Life Research, 17, 437-45.

Shah SA, Neoh HM, Rahim SS, et al (2014). Spatial analysis of colorectal cancer cases in Kuala Lumpur. Asian Pac J Cancer Prev, 15, 1149-54.

Silva; JPCMd. EORTC QLQ CR-29 evaluation in 500 patients with colorectal cancer. 2012 Gastrointestinal Cancers Symposium, 2012. J Clin Oncol.

Sprangers MAG, te Velde A, Aaronson NK, et al (1999). The construction and testing of the EORTC colorectal cancerspecific quality of life questionnaire module (QLQ-CR38). European Journal of Cancer, 35, 238-47.

Thaysen HV, Jess P, Laurberg S, et al (2012). Validation of the Danish version of the disease specific instrument EORTC QLQ-CR38 to assess Health-related quality of life in patients with colorectal cancer. Health and Quality of Life Outcomes, 10.

Tsunoda A, Yasuda N, Nakao K, et al (2008). Validation of the Japanese version of EORTC QLQ-CR38. Quality of Life Research, 17, 317-22.

Ulaganathan V, Kandiah M, Zalilah MS, et al (2012). Colorectal cancer and its association with the metabolic syndrome: a Malaysian multi-centric case-control study. Asian Pac J Cancer Prev, 13, 3873-7.

Wan Puteh SE, Saad NM, Aljunid SM, et al (2013). Quality of life in Malaysian colorectal cancer patients. Asia Pac Psychiatry, 5, 110-7.

Whistance RN, Conroy T, Chie W, et al (2009). Clinical and psychometric validation of the EORTC QLQ-CR29 questionnaire module to assess health-related quality of life in patients with colorectal cancer. European Journal of Cancer, 45, 3017-26. 